\title{
MEMÓRIAS DE UMA EXPERIÊNCIA DE TRINTA DIAS EM MAPUTO-MOÇAMBIQUE
}

\author{
MEMORIES OF A THIRTY-DAY EXPERIENCE IN MAPUTO-MOZAMBIQUE
}

"As mulheres não esperam: partiram para a batalha Com os olhos grávidos de sonhos E novas decisões." João Melo

\section{RESUMO}

Este artigo resultou da participação no Projeto "Práticas sociais e saberes de mulheres e homens e a produção do território rural no Distrito de Marracuene em Moçambique: viabilidade das alternativas produtivas no mundo da sustentabilidade", desenvolvido de 2013 a 2017 e estruturado sob uma proposta interdisciplinar e interinstitucional. A minha atuação no referido projeto, no que tange ao contato direto com a população, compreendeu a experiência de permanência em Maputo-Moçambique por trinta dias. O objetivo neste texto é o de apresentar minhas impressões deste período, com o olhar voltado às mulheres e à produção de suas próprias vidas, seja material ou imaterial, por meio de uma metodologia de aproximação e de respeito às diversidades culturais e à organização do trabalho. As observações, os diálogos, os registros em caderno de campo e fotográficos ocorreram em espaços rurais e urbanos, em locais de produção de alimentos e de sua comercialização. Os resultados são indescritíveis. O que ora apresento são manifestações de conhecimentos coletivizados e demonstro, também, relevância em valorizar os aprendizados compartilhados entre os dois países de modo respeitoso, rompendo com as hierarquias impostas pelo conhecimento científico, quando nega ou exclui os saberes tradicionais e os modos de vida alicerçados em culturas díspares.

Palavras-chave: Mulheres. Trabalho. Rural e Urbano. Cotidiano.

\section{ABSTRACT}

This article is a result of the participation in the Project "social practices and women and men knowledge and the production of the rural territory in the Marracuene district in Mozambique: the viability of the productive alternatives in the world of the sustainability", developed between 2013 and 2017 and structured based on an interdisciplinary and interinstitutional proposal. My role in the mentioned project, in what is related to the direct contact with the population, took me 30 days of a permanence experience in Maputo-Mozambique. The aim of this text is to present my own impressions of this period, by looking at women and their own lives production, whether material or immaterial, by an approach and respect methodology to the cultural diversities and to the work organization. The observation, dialogues, photographic records and in the field notebook, occurred in rural and urban spaces, in areas of food production and commercialization. The results are indescribable. What I present here, are manifestations of collective knowledge and I show, as well, relevance to value the shared learning between the two countries in a respectful way, breaking the hierarchies imposed by the scientific knowledge, when it denies or excludes the traditional knowledge and the ways of life grounded on disparate cultures.

Keywords: Women. Work. Rural and Urban. Daily.

\section{Marisa de Fátima Lomba de} Farias $^{\text {a }}$

a Universidade Federal da Grande Dourados (UFGD), Dourados, MS, Brasil

DOI: $10.12957 /$ geouerj.2020.53707

Correpondência:marisa.lomba@ufgd.edu.br

Recebido em: 30 nov 2019

Revisado em: 11 mai. 2020

Aceito em: 30 mai. 2020 


\section{O MEU OLHAR...}

O primeiro olhar para as mulheres de Moçambique, especificamente na capital Maputo, ocorreu por meio de um convite para participar da equipe do Projeto "Práticas sociais e saberes de mulheres e homens e a produção do território rural no Distrito de Marracuene em Moçambique: viabilidade das alternativas produtivas no mundo da sustentabilidade", desenvolvido de 2013 a 2017 e estruturado sob uma proposta interdisciplinar $^{1}$ e interinstitucional ${ }^{2}$.

A imaginação sobre as vidas das mulheres daquele país se abriu para mim e, imediatamente, sentimentos "combinados" foram impulsionados por uma curiosidade científica, por sensações de prazer, de insegurança e, ao mesmo tempo, de responsabilidade, enfim; múltiplos afetos e ambiguidades tomaram conta do meu corpo e da minha subjetividade. Não havia pensado em tal possibilidade: atravessar o Atlântico, ir até o Índico e conviver com mulheres que considerava - e, atualmente, mais ainda - fortes, corajosas, determinadas e lindas em todos os sentidos.

Nos meses que antecederam a viagem - com permanência prevista de trinta dias em Maputo - em encontros do grupo de pesquisa e eventos, eu expressava minhas diversas preocupações "misturadas". As minhas manifestações, às vezes, sem muito sentido para algumas pessoas, pareciam as de uma iniciante em pesquisa. Era possível observar os olhares e os sorrisos que partiam de algumas pessoas, mas isso não me importava; era preciso evidenciar a minha preocupação: a de construir um diálogo sem hierarquias e etnocentrismos para com aquelas pessoas e seus lugares de moradia e de trabalho, sem que avaliações ou juízos de valor pairassem sobre nossas posturas, frases e procedimentos teórico-metodológicos. É um engano, às vezes até proposital, pensar na postura ética "incondicional" e compromissada de pesquisadores/as relacionada aos grupos com singularidades marcantes.

De tais circunstâncias, reforcei minha concepção de pesquisa, enquanto um caminho individual e coletivo de e para a construção de conhecimentos, que são elaborados por muitas pessoas, em universidades ou não, em lugares distantes e em condições inusitadas. Não há um conhecimento que seja superior ao outro; os conhecimentos devem dialogar com respeito à diversidade de pensamento, de cultura, de modo de vida; eles se complementam e não se neutralizam em nome de um saber científico dominado por vaidades e competições.

\footnotetext{
${ }^{1}$ A equipe era formada por pesquisadores/as e estudantes de graduação e pós-graduação das áreas de Geografia, Sociologia, História, Psicologia.

${ }^{2}$ As instituições participantes foram: Universidade Federal da Grande Dourados (UFGD) e Universidade Eduardo Mondlane (UEM).
} 


\section{Outros olhares...}

O principal objetivo do Projeto foi o de analisar a produção do território rural, na perspectiva da geração de trabalho e de renda e os aspectos que envolvem a permanência das famílias na terra. Para o alcance desse objetivo, a atividade turística foi referência para as ações propostas em uma expectativa ao turismo comunitário, pautado na coparticipação de camponeses/as no processo de autogestão em todas as atividades e na valorização das manifestações culturais.

Projetos de intercâmbio entre instituições estrangeiras e o encontro com culturas diferentes, as oportunidades de envolvimento acadêmico e de trabalho em equipe demonstram a preocupação em construir conhecimentos libertos de uma razão instrumental, encontrada nas universidades que, em certos casos, são responsáveis por paralisar a capacidade analítica criativa ${ }^{3}$.

O contato com realidades diversas, multiculturais, conflituosas ampliou os olhares para campos materiais e subjetivos, talvez, não observados da mesma maneira em outros momentos e lugares. A realidade que encontramos chamou a atenção para perspectivas mais contextualizadas e mais críticas, pois quem faz parte dela diretamente, nesse caso, as pessoas de Moçambique ${ }^{4}$, especialmente de Maputo, instituem sua amplitude, riqueza, beleza, sentidos e significados, entrecortados por memórias de vidas passadas e presentes.

A equipe se apropriou de teorias que fomentaram o diálogo criativo, respeitoso e valorativo com as pessoas. Elas vivem especificidades, quanto à experiência de dignidade humana e de visão de mundo, que as distanciam de modelos dominantes na sociedade ocidental. Adotou-se, então, uma postura entrecruzada por conhecimentos científicos e por aqueles de raízes nativas, locais e tradicionais sem hierarquias (SANTOS; MENESES; NUNES, 2005, p. 54).

A permanência em Moçambique nos fez conviver em um território multicultural apropriado diferentemente por pessoas, grupos, comunidades, onde "fincaram suas raízes" e defendem seu modo de vida em meio a indecisões relativas às mudanças sociais, econômicas, políticas, geracionais e de gênero. Vivem entre o existente e o que há por vir. Não há caminhos lineares, mas avanços, recuos e reconfigurações, fortalecidos por fragmentos da memória e da cultura própria

Alguns exemplos podem ser registrados, já que a observação direta, as anotações no caderno de campo, as entrevistas e as conversas informais permitiram trazer: as formas de produção familiar para a

\footnotetext{
${ }^{3} \mathrm{~A}$ contribuição da CAPES é inegável no sentido de fomentar conhecimentos por meio de projetos e, que continue atenciosa para temas relevantes como esse.

${ }^{4}$ Falo no país Moçambique e na capital Maputo, entretanto, a minha permanência se efetivou na capital, com visitas a algumas cidades mais próximas, como descrito na nota de rodapé n. 8.
} 
sobrevivência ${ }^{5}$; as diferentes concepções sobre a realidade social apresentada por estudantes ${ }^{6}$; a organização turística em Maputo e nos distritos ${ }^{7}$; as características da organização de movimentos sociais ${ }^{8}$; as características urbanas, espaços e manifestações culturais ${ }^{9}$

Durante os trinta dias de permanência em Moçambique, ocorreram dificuldades, desencontros, entrevistas e visitas negadas em algumas instituições (condições que fazem parte da pesquisa). Conviveu-se com uma racionalidade burocrática e com formalidades intensas que atravessavam as relações entre pessoaspessoas, pessoas-instituições, instituições-instituições naquele país. Esse tempo e as vivências revelaram um cenário político ávido de democracia e de participação da sociedade civil.

Em diversos âmbitos, ouvia-se considerações sobre as dificuldades do país, sobre os problemas com o trânsito, transporte urbano, desemprego, saúde, violência e guerra. E, ao mesmo tempo que as pessoas indicavam resistência e crença em dias melhores, os conflitos vividos e pressentidos eram o fio condutor de um discurso que responsabilizava a estagnação do país à situação degradante vigente.

Observou-se o cotidiano da população nas ruas, em vários espaços urbanos e rurais, que utiliza meios de transportes "desumanos". As pessoas convivem com a ausência de saneamento básico, as habitações são inadequadas e o acesso às políticas públicas, irregulares e inconsistentes no país, é precário.

Empiricamente, verificou-se a ausência de coleta de lixo em regiões periféricas da cidade, sendo que, no entorno da universidade e onde está localizado um número significativo de ONGs e Embaixadas, esse serviço ocorre periodicamente.

\footnotetext{
${ }^{5}$ Observação direta de formas de produção familiar e de subsistência ocorreu em duas localidades: Zona Verde no Bairro Bagamiuyo no Distrito Kabucuana em Maputo e no Distrito Urbano no 6 na Província de Matola em Moçambique.

${ }^{6}$ Palestras/Aulas na Universidade Eduardo Mondlane em duas turmas na Faculdade de Letras e Ciências Sociais, Curso de Antropologia da Universidade Eduardo Mondlane.

7 Visita à Província de Gaza nos distritos de Chindenguele e Xai-Xai, aos Distritos de Catembe e Macaneta para contato e conversas com atendentes e trabalhadores/as do turismo local, com administradores de equipamentos comerciais de turismo (restaurantes/lanchonetes), com equipe de atendimento de resorts, com pescadores.

${ }^{8}$ Reunião com dirigentes da União Nacional de Camponeses (UNAC), entrevista com dirigentes do Fórum Mulher de Maputo, participação em curso de capacitação de Lideranças de Mulheres (Fórum Mulher) em Maputo

${ }^{9}$ Observações nos lugares visitados como a Feira dos Continuadores, o Centro Cultural Francomoçambicano, a Praça dos Namorados, o Museu da História Natural da UEM, o Museu Histórico Nacional, o Palácio dos Casamentos; Atenção aos programas de rádio e televisão Palácio, além contatos nas ruas, na universidade, no comércio informal, em feiras, supermercados, etc.;
} 
Figura 1. Bairro Periférico de Maputo. Fonte: FARIAS, 2015. Trabalho em campo-Maputo.

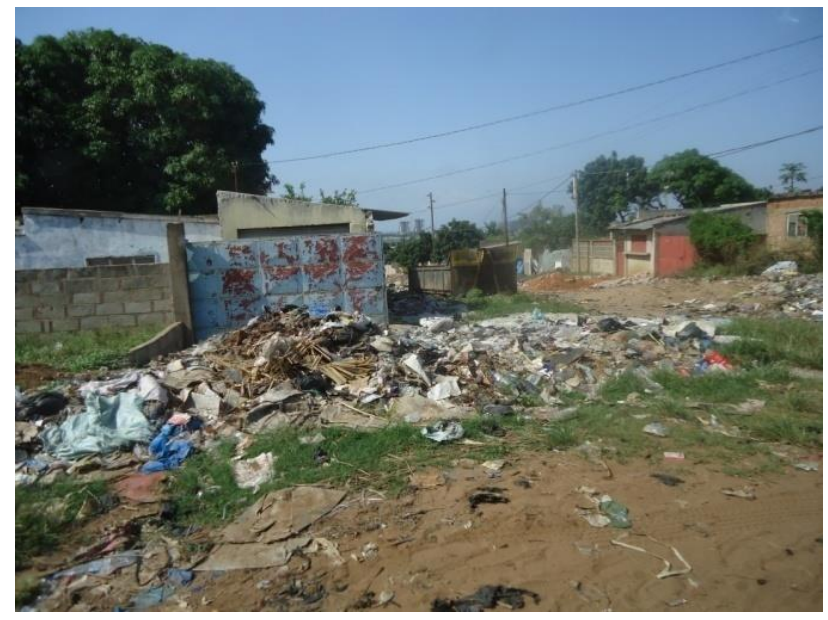

As pessoas se dedicam ao trabalho, criam alternativas de sobrevivência material e imaterial, convivem com as dificuldades, constroem resistências cotidianas, embaladas por músicas, danças, cabelos artisticamente arrumados, movimentos de corpos como lugares de ações libertas, criativas e alegres. São muitas ambivalências. As pessoas se fazem entre perdas e recriações, ressignificam os matizes culturais com "tonalidades" tradicionais - por muitos grupos, consideradas atrasados - e "tonalidades" modernas reforçadas pelo capitalismo com seus tentáculos que se entrelaçam entre as estruturas e as subjetividades.

A busca por dias melhores, com direitos reconhecidos e qualidade de vida é um anseio legítimo da população diante da ausência de políticas públicas que poderiam favorecer a cidadania a essa população, expropriada de direitos básicos como saneamento, transporte eficiente e com qualidade, acesso à saúde, à educação.

Há uma hierarquia social visível na apropriação dos recursos existentes; um exemplo disso é o uso dos meios de transporte, que demarca posições de grupos e relações de poder, além da desigualdade econômica. Ao mesmo tempo em que se convive com a presença de carros luxuosos; aos/às trabalhadores/as são disponibilizados meios de transporte insuficientes, sem qualidade e sem segurança mínimas para o deslocamento diário. 
Figura 2. Um dos tipos de transporte público. Fonte: CAMPOS, 2015. Trabalho em campo-Maputo.

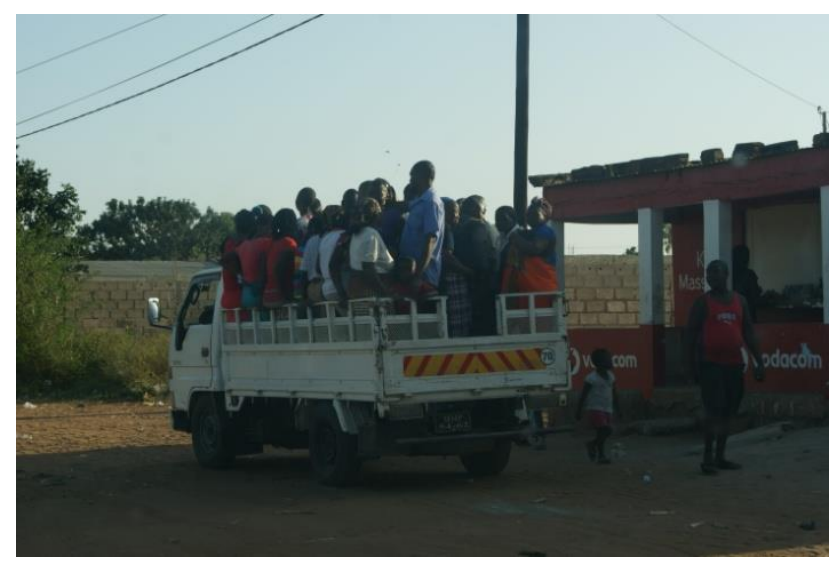

Essa precariedade compromete a vida e a saúde desse grupo, visto que é obrigatório o despertar muito cedo - ainda de madrugada, por volta de $4 \mathrm{~h}$. a $5 \mathrm{~h}$. - e o retorno para casa ocorre muito tarde - por volta de $21 \mathrm{~h}$. às $22 \mathrm{~h}$. - conforme relatos de pessoas entrevistadas, ou seja, pouco tempo é disponibilizado ao convívio coletivo e ao dia a dia das famílias.

Em Maputo, as políticas públicas não proporcionam os direitos fundamentais, com o exemplo apresentado acima relativo ao transporte público (Figura 2). Um dos motivos para a continuidade da falta de direitos está na hierarquia política organizada por meio de privilégios ao grupo político que está no poder e na concentração de renda visível na capital.

\section{Memórias de uma experiência}

Como já foi possível intuir, esse projeto desenvolvido durante quatro anos (2013 a 2017) trouxe à tona multiculturalidades e conflitualidades do território Moçambicano. Cada pesquisador/a olhou para este território por entre seus saberes e experiências, tanto pessoais, quanto de pesquisas desenvolvidas.

Neste momento, as minhas percepções serão registradas como um relato de experiência de trinta dias de convívio com mulheres em alguns espaços sociais. Elas vivem situações singulares em territórios apropriados por vidas em diálogo com a natureza e para a produção de alimentos, como se constatou diante da presença marcante e fundamental do rural entrelaçado ao urbano.

São realidades em movimento constante que interferem no modo de vida e forçam novas configurações para a sobrevivência, com vistas a superar as dificuldades econômicas cotidianas, além de vivenciarem o 
domínio de uma política de ausência quase total do Estado, voltado aos interesses político partidários bastante excludentes.

No período de permanência em Moçambique, foram estabelecidos diálogos com as mulheres em diversos lugares, com registros orais ${ }^{10}$ e fotográficos das ações, das formas de organização, do trabalho em machambas ${ }^{11}$. Foram observados o comércio informal, a arquitetura, o trânsito e as formas de locomoção, a territorialidade, enfim, aspectos do cotidiano urbano e rural.

Dentre as técnicas de registro, as fotografias permitiram dialogar com o imaginário social e com as relações sociais, sendo que outras não teriam a mesma capacidade, como por exemplo, apresentar machambas para além de apenas falar sobre elas.

Figura 3. Machambas Visitadas. Fonte: FARIAS, 2015. Trabalho em campo-Maputo.

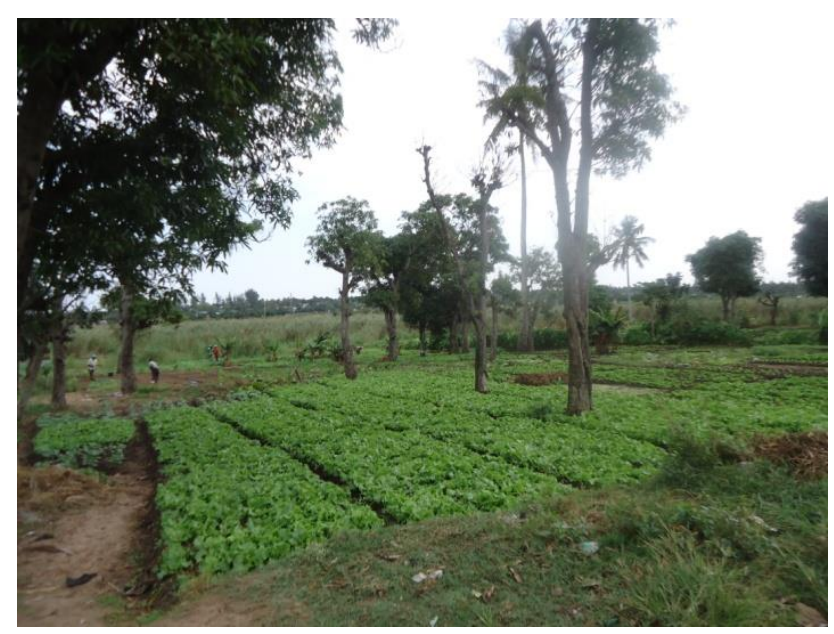

Como a produção toma forma no território:

\footnotetext{
10 Registradas com entrevistas semiestruturadas.

${ }^{11}$ Foram visitadas Machambas/União Geral de Cooperativas das Zonas Verdes do Bairro de Infunele (Cinturão Verde da cidade de Maputo, para observação e realização de entrevistas com mulheres camponesas/urbanas que produzem alimentos para o sustento das famílias, comercialização no mercado interno municipal e nos próprios locais.
} 
Figura 4. Organização de uma Machamba. Fonte: FARIAS, 2015. Trabalho em campo-Maputo.

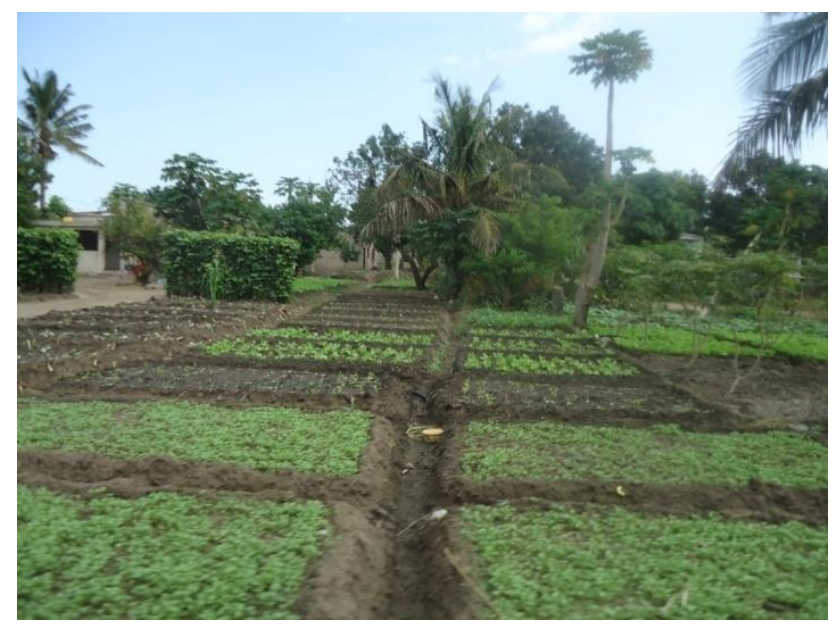

A seguir, a produção de mandioca em uma machamba localizada à beira de uma estrada aos arredores de Maputo, por onde a equipe passou. Naquele momento, a mulher e as crianças, com muito entusiasmo, permitiram que as fotos fossem tiradas.

Figura 5. Produção de uma Machamba. Fonte: CAMPOS, 2015. Trabalho em campo-Maputo.

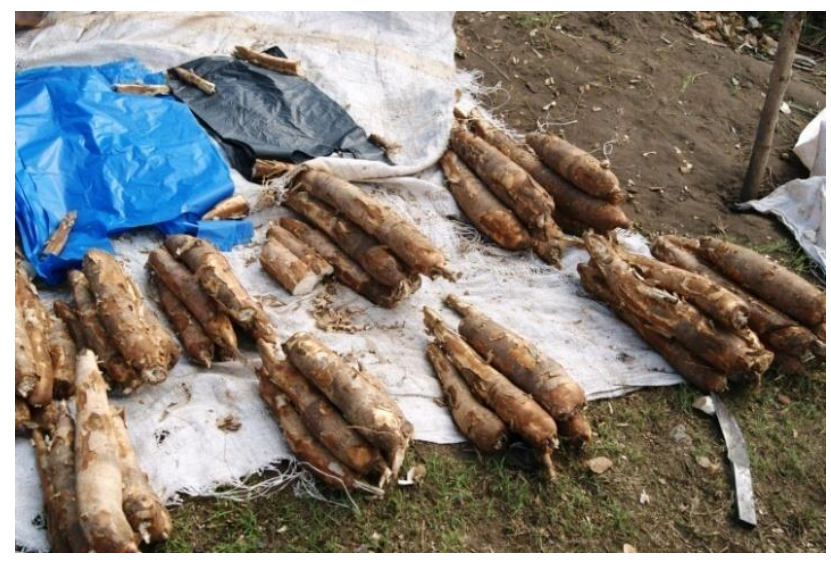

Figura 6. As mãos que produzem alimentos. Fonte: CAMPOS, 2015. Trabalho em campo-Maputo.

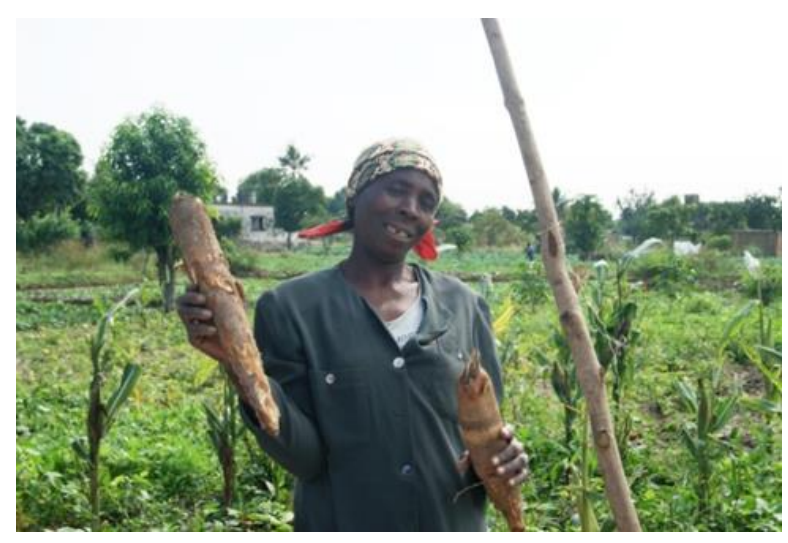


Figura 7. Vidas que produzem alimentos. Fonte: CAMPOS, 2015. Trabalho em campo-Maputo.

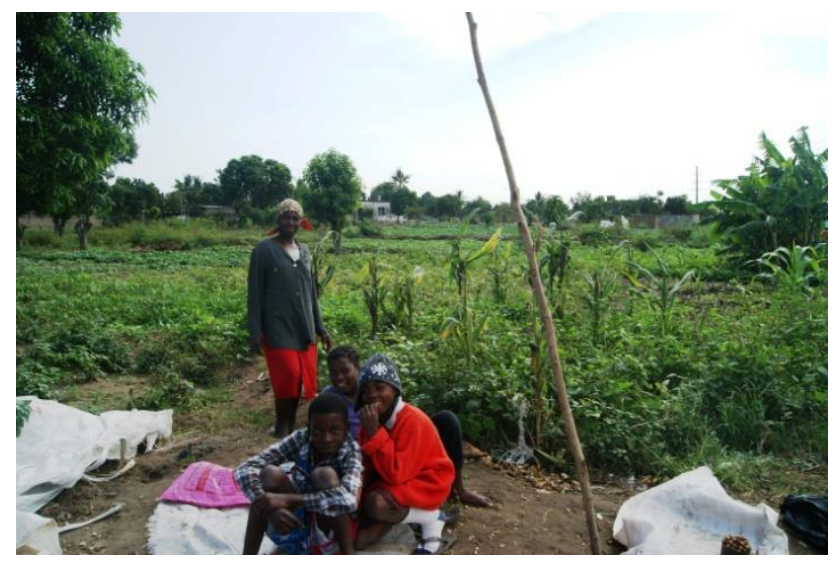

Estamos a demonstrar um dos produtos, como tantos outros, comercializados na Feira de Marracuene e no Mercado Municipal de Maputo. São lugares predominantemente femininos, neles as mulheres são representativas por entre o colorido dos produtos e das kapulanas referenciando identidades de mulheres, trabalhadoras, sorridentes e curiosas diante da nossa presença. A curiosidade rapidamente se dissipava; o diálogo fluía sem muitas delongas.

\section{Sábado na Feira de Marracuene}

A equipe se deslocou para a Feira de Marracuene no sábado. De longe já se avistava muitas pessoas, cores, árvores e ouvia-se vozes que ressoavam de longe. Os sons e os diversos dialetos se entrecruzavam às manifestações de turistas a procura de algum produto, quase sempre uma novidade para se presentear, lembranças para serem levadas aos seus países. Tudo isso se intercalava à fumaça com aroma de comida, uma das mais comuns de lá: o frango assado.

Figura 8. Visão Geral da Feira. Fonte: CURADO, 2015. Trabalho em campo-Marracuene.

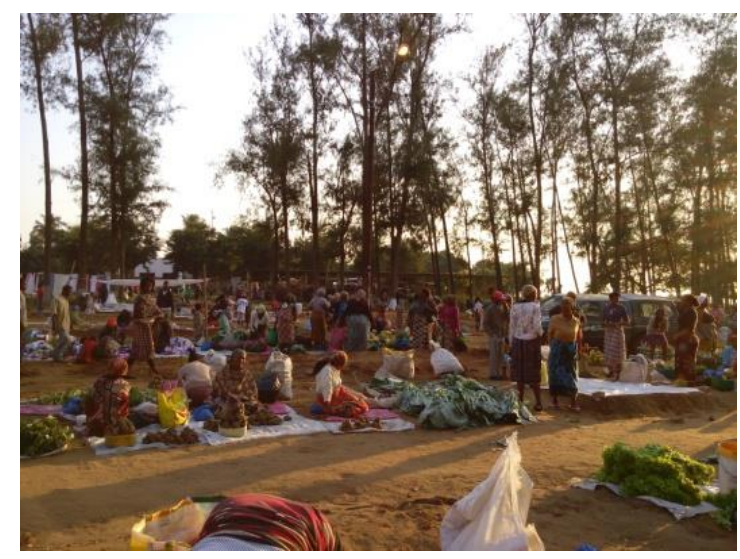


A feira é um espaço-tempo prioritariamente feminino, mulheres de várias gerações e suas crianças, na maioria, meninas com os cabelos embelezados por bolinhas multicoloridas, davam vida ao lugar muito colorido (repleto de tons e sons), movimentado e barulhento. As crianças acompanhavam suas mães na comercialização dos produtos e, nessa atividade, várias eram as suas responsabilidades: carregar os produtos e organizá-los para a comercialização, vendê-los, cuidar de irmãs e de irmãos, e, ainda, traduzir a conversa entre os turistas e as mulheres que se comunicavam apenas em seu (ou dialeto), especialmente, aquelas de mais idade.

Os meninos, como se espera de culturas com traços patriarcais, se dedicavam às tarefas de maior "prestígio" e inter-relacionadas com o lazer - para o olhar do "estranho": conduziam os produtos em carrinhos, carriolas que, quando vazios, transformavam-se em lugares de descanso para eles. Os meninos corriam nos espaços da feira, pulavam e gritavam, ao contrário das meninas.

Essas mulheres fazem da feira o espaço-tempo de reprodução da vida; um processo identitário de longa data está implícito entre elas e o que produzem. Os seus corpos e olhares, as frases nem sempre compreendidas por quem está de passagem, a organização e a exposição dos produtos são os sentidos e os significados de subjetividades singulares. Não se trata de mera formalidade, mas de reciprocidade subjetiva com o seu trabalho para a continuidade da vida de pessoas, famílias, grupos e gerações.

$\mathrm{Na}$ feira são encontradas diversas manifestações culturais, linguísticas, de organização grupal, de trabalho feminino, de experiências infantis, uma extensão da vida das comunidades onde tudo é produzido e consumido e, então, levado para o comércio. Há, para mim, um diálogo entre as manifestações culturais desses grupos com uma especificidade feminina, com muito a ensinar sobre resistência, criatividade, produção, para quem chega com outras culturas e significados diversos para a produção e para o consumo de alimentos. A seguir, trago o registro de um momento de diálogo entre a pesquisadora e Dona Rosa.

Figura 9. Pesquisadora Marisa e Dona Rosa na Feira. Fonte: CURADO, 2015. Trabalho em campo-Marracuene.

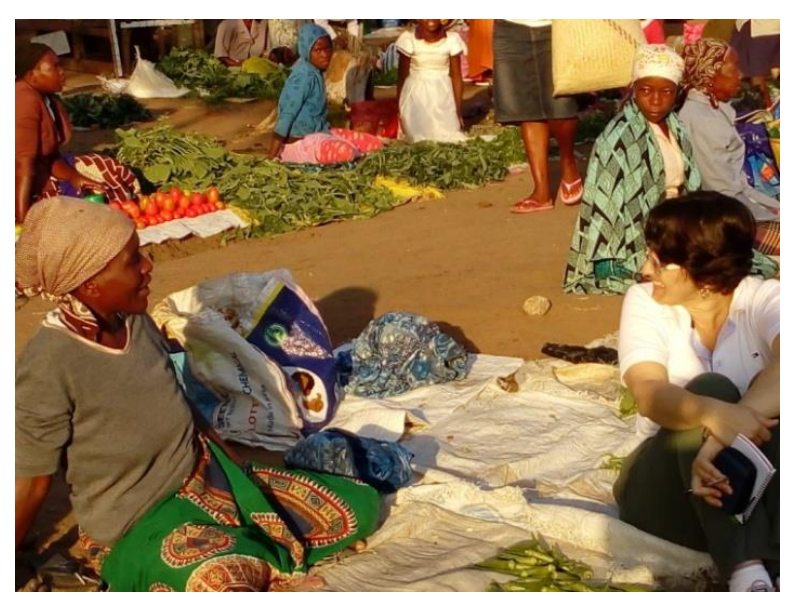


O Mercado Central de Maputo: o entrelugar urbano e rural

O outro momento de diálogos entre a equipe e as mulheres, ocorreu no Mercado Central de Maputo ${ }^{12}$. Foi possível observar a organização do dia de trabalho feminino e as características do lugar com uma dinâmica identitária similar à da feira de Marracuene. Os produtos ali comercializados acompanhavam os mesmos atributos; o diferencial está na comercialização em área urbana. Desse aspecto decorre a vivacidade das mulheres que permanecem no entrelugar rural e o urbano: elas produzem e comercializam a produção de "suas" machambas e de outras mulheres.

Não foram encontradas crianças nesse espaço (somente bebês), o que pode levar a considerar as especificidades das experiências infantis a partir do campo e da escola.

Segue uma fotografia de Dona Fismina, em meio aos seus produtos.

Figura 10. Mercado Municipal (Dona Fismina Agostin). Fonte: CAMPOS, 2015. Trabalho em campo-Marracuene.

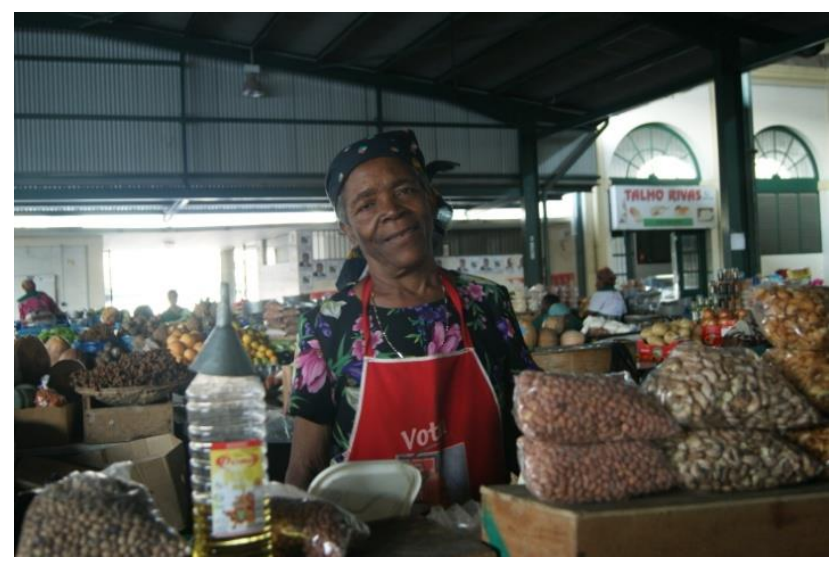

No primeiro momento, as mulheres do mercado se mostraram curiosas e desconfiadas dos nossos objetivos; a nossa presença foi relacionada à de muitos/as turistas que desejam, meramente, a aquisição de algum produto e, para isso, solicitam preços abaixo do estipulado por elas. Há por parte deste grupo, reações de desmerecimento, invisibilização e etnocentrismo para com o trabalho criativo dessas pessoas.

${ }_{12}$ Mercado Central de Maputo (Conselho Municipal de Maputo), onde foram realizadas entrevistas com mulheres feirantes e registro fotográfico. 
Figura 11: Mercado Municipal. Fonte: CAMPOS, 2015. Trabalho em campo-Marracuene.

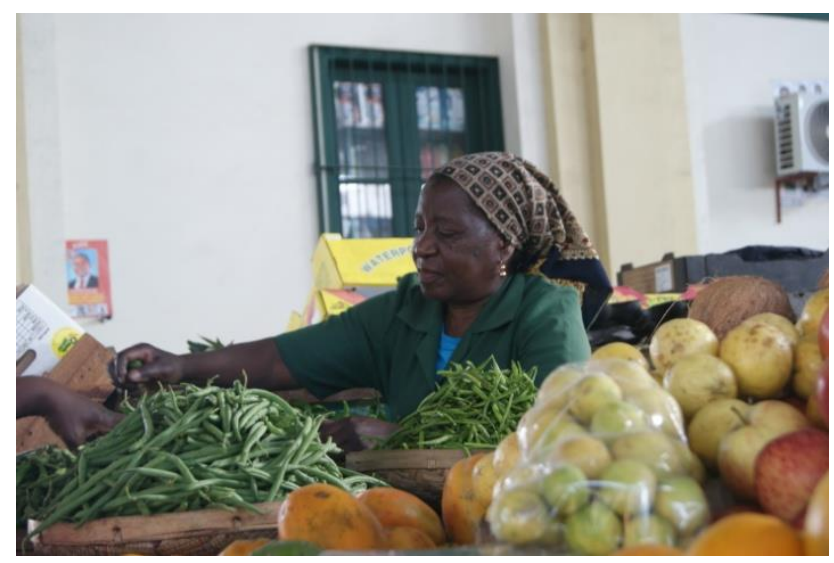

Dito isso, é importante salientar dois aspectos: as fotografias das mulheres no mercado foram reveladas e entregues a elas, isso gerou satisfação, autorreconhecimento e confiança para com a equipe da pesquisa. A mesma opção ocorreu com um artesão da Feira de Continuadores, o único que permitiu ser fotografado. Todos os lugares visitados foram fotografados - o território como um todo - e, considerando a questão ética, as pessoas eram consultadas para obtenção de permissão para o registro ${ }^{13}$.

Diante das fotografias desse cotidiano, a vida cultural e de resistência pôde ser observada. As mulheres e suas atividades rotineiras foram o centro e núcleo do olhar de quem fotografou, em diálogo com os objetivos do projeto e com a equipe, que esteve junta em todas as atividades realizadas em Moçambique. A fotografia, segundo Martins (2008, p. 33) "é uma das formas de expressão visual da realidade social”.

Para o autor (2008, p. 31), esta técnica permite: “[...] religar o repetitivo e o inovador na vida social e o que é fantasioso com o que é objetivo.", por isso as fotografias demonstraram em suas entreimagens, aspectos da cultura em Moçambique, repetitivos há anos e arraigados nos corpos, na memória, no imaginário da população e as transformações paulatinas desse processo; nem sempre antigo e nem sempre novo. E mais... Nos resultados aparentes das imagens, é possível vislumbrar um real que ainda não é realidade, é mais um possível, um alumbramento, um fantasioso, um sonho de corpos e mentes que são desejantes.

Tanto na feira quanto no mercado, foram utilizadas as fotografias para uma releitura das experiências da comercialização de alimentos. As bancas são organizadas com produtos diversificados de acordo com a produção nas machambas; vão desde doces, farinhas até remédios, plantas medicinais ou mesmo produtos in natura. Há certas características definidas pelas mulheres - sem uma perspectiva essencialista - percebida no modo de organização dos produtos, colocados um a um, combinados por tipos, cores e quantidades, que

13 Permissão oral. 
talvez queiram revelar outros valores além dos monetários; a comunicação com turistas, pessoas da localidade e entre si.

Não há uma insistência por parte das mulhers para a aquisição de seus produtos, atitude verificada entre os homens, que na maioria estão nas feiras de artesanato e apresentam uma postura de quase "perseguição" para a compra de algo que estão a oferecer.

\section{FINALIZAR O QUE NÃO TEM PONTO FINAL}

A realização do Projeto, aqui mencionado, resultou em conhecimentos que foram socializados entre as equipes com igualdade de importância, sem hierarquias ou valores com escalas diferentes, conforme o grau de formação acadêmica ou atividade exercida.

A convivência entre as equipes, o contato com pessoas nas ruas, a observação nos locais visitados, as entrevistas realizadas, as aulas ministradas, todas as atividades desenvolvidas em 30 dias, mostraram traçados de uma história vivida, narrada e escrita com muito esforço, por mulheres, homens, jovens e crianças, para a reconstrução de um país de duríssima e sofrida independência de Portugal e constantemente agredido por conflitos armados.

O contato direto com a população, a observação atenta dos espaços sociais, dos movimentos de pessoas, dos diálogos em alta voz nas ruas onde é realizado o comércio informal, da variedade da alimentação produzida nas machambas, dos coloridos das kapulanas, ratificou a constatação da presença histórica das mulheres na organização social, política e econômica de Moçambique. Um grupo que gradativamente se emancipa e ocupa espaços importantes e de destaque na vida social e política daquele país.

A novidade, o moderno e o promissor estão nas contradições e nos conflitos gerados por uma realidade multifacetada que altera diretamente a vida dessas pessoas que, ao mesmo tempo, resistem a isso, frente à massificação da sociedade que valoriza o mercado e o consumismo, espraiado por todos os cantos do planeta.

Trata-se de um território em que algumas verdades são questionadas, outras incorporadas em processos subjetivos de representação do social e do vivido por essa população, majoritariamente feminina, responsável pela reprodução econômica e social de suas famílias, além de sustentarem o comércio local e mais amplo do país.

Diante dos relatos e dos documentos estudados, em Moçambique, muitas mulheres e famílias migraram para a área urbana, "obrigadas" pela situação de conflitos, e relembram com tristeza, da perda da terra, dos animais e da moradia. As cidades engoliram-nas, mas elas sobrevivem com a saudade e com as lembranças 
dos resquícios do modo de vida. Percebe-se que o rural está no cotidiano das mulheres como um alicerce da memória.

Algumas famílias reconfiguram esse modo de vida em suas machambas próximas à cidade com o risco, também, de serem "engolidas" pela urbanidade descontínua, confusa e excludente e pelo capitalismo. Uma produção de alimento e de existência liderada por mulheres, trata-se de um saber-fazer feminino internalizado ao longo do tempo e, por isso, não há conhecimento científico ou pesquisas que possam ensinar o que fazer, como fazer e para que fazer a essas mulheres, a essa população. (WHITAKER, 2002).

Tais saberes e fazeres devem ser contemplados e incorporados em propostas, pesquisas ou alternativas de melhoria de vida a serem apresentadas às mulheres, que apreenderam preceitos sobre qualidade da alimentação, técnicas de produção, construção de moradias, alternativas de medicamentos, dentre tantas outras técnicas e outros conhecimentos "que carregam como herança cultural."

Isso não quer dizer que alternativas "prontas" serão levadas aos diferentes lugares. Os grupos e comunidades podem, a partir de diálogos e espaços de reflexão, fazer suas escolhas e definir os seus caminhos autonomamente, com aportes objetivos (materialidade da vida) e subjetivos que são íntimos e incentivam comportamentos e visões de mundo em uma relação dialética. Essas subjetividades produzem sentidos para a vida em constante movimento.

As subjetividades femininas não são ditas ou apresentadas facilmente porque instituem um processo amplo de construção de sentidos na convivência social, perante as experiências individuais e os desafios por sermos mulheres com uma carga histórica de responsabilidades sobrepostas e alicerçadas em modelos patriarcais de comportamento.

Diante das interferências social, cultural e histórica, as subjetividades são constituídas cotidianamente, consciente e inconscientemente, quando as mulheres orientam a sua ação no mundo. Permanece uma correlação entre mulheres e territórios, mulheres entre si, mulheres e homens, mulheres e instituições, mulheres e grupos/comunidades, enfim, estrutura-se movimento dialógico na vida cotidiana.

Esses trinta dias foram momentos de significativa sociabilidade entre mulheres de dois países Moçambique e Brasil; experiências foram socializadas e não há palavras que caracterizem o meu aprendizado. Técnica alguma consegue abarcar um universo de vida, trabalho e sociabilidade tão intenso e resistente aos problemas do cotidiano, tanto em âmbito amplo, cenário político inseguro, quanto íntimo, as transformações identitárias e culturais. Nenhuma técnica de pesquisa suporta aquela experiência que continua fluindo e que, em muitos aspectos, prossegue indizível. 
Como pesquisadora que desenvolve pesquisas em assentamentos rurais, com referenciais teóricometodológicos que dialogam com perspectivas de gênero, história das mulheres, economia solidária, metodologia participante e movimentos sociais, foi uma oportunidade para ampliar o comprometimento com as populações que vivem à "margem" dos processos políticos, sociais e econômicos. São pessoas que constroem essa história, com alegria, dignidade e lutam por seus direitos, seja no campo, seja na cidade.

Histórias de grupos entrecruzadas em tempos e espaços diferentes, com modos de vida peculiares, mas próximos ao se considerar a história e a memória que transita por continentes e países. As populações são marcadas por trajetórias de resistências comuns, contra a miséria, expropriação da terra, desigualdade social, dentre outras e criam rupturas que são lentas, todavia, contínuas diante das relações de poder.

\section{REFERÊNCIAS}

ALONSO, Margarita Flórez. Proteção do conhecimento tradicional. In: SANTOS, Boaventura de Sousa. Semear outras soluções: os caminhos da biodiversidade e dos conhecimentos rivais. Rio de Janeiro: Civilização Brasileira, 2005.

CAMPOS, Bruno Ferreira. Fotografias. Maputo, 2015.

CASIMIRO, Isabel Maria. “Paz na Terra, Guerra em Casa”. Feminismo e Organização de Mulheres em Moçambique. Maputo: Promédia, 2004, (Coleção Identidades).

CERTEAU, Michel de; GIARD, Luce; MAYOL, Pierre. A Invenção do Cotidiano: morar, cozinhar. 2. ed. Petrópolis, RJ: Vozes, 1998. CURADO, Jacy Corrêa. Fotografias. Maputo, 2015.

FARIAS, Marisa de Fátima Lomba. Fotografias. Maputo, 2015.

MARTINS, José de Souza. Sociologia da Fotografia e da Imagem. São Paulo: Editora Contexto, 2008.

MONDLANE, Eduardo. Lutar por Moçambique. Maputo: Coleção Nosso Chão, 1995. (1ạ Edição Moçambicana).

RIVAR, José. História da África. São Paulo: Editora Contexto, 2013. (Coleção História da África).

SANTOS, Boaventura de Sousa; MENESES, Maria Paula G. de; NUNES, João Arriscado. Introdução: Para ampliar o cânone da ciência: a diversidade epistemológica do mundo. In: SANTOS, Boaventura de Sousa. Semear outras soluções: os caminhos da biodiversidade e dos conhecimentos rivais. Rio de Janeiro: Civilização Brasileira, 2005.

WHITAKER, Dulce C. A. Sociologia Rural: questões metodológicas emergentes. Presidente Venceslau, SP: Editora Letras à Margem, 2002. 